\title{
Investigating Symmetrical and Asymmetrical Cointegration of the Factors Affecting the Passenger Rail Demand in Tehran Province
}

\author{
Mohammad Reza Kohansal (Ph.D)*1, Sasan Torabi ${ }^{2}$ \\ 1- Professor, Agricultural Economics Department, Ferdowsi University of Mashhad, Mashhad, \\ Iran, Kohansal@um.ac.ir \\ 2- Ph.D Student of Agricultural Economics, International Campus of Ferdowsi University of \\ Mashhad, Mashhad, Iran, sassan_torabi@yahoo.com \\ *Corresponding Author: Mohammad Reza Kohansal
}

DOI: 10.6007/IJARBSS/v5-i5/1607 URL: http://dx.doi.org/10.6007/IJARBSS/v5-i5/1607

\begin{abstract}
The current paper investigates the factors affecting rail transportation demand using econometric time series in Tehran province. To this end, first the Augmented Dickey-Fuller (ADF) test and then the Johansen cointegration test were applied respectively to study the stationarity of variables of the model. After assuring the stationarity of the variables, Johanson test is applied to assess the balanced and long-term their relationship. The results are indicative of a balanced and long-term relationship. Then Vector Auto Regression Model (VAR) was applied to investigate the dynamism using the two criteria of Impulse Response Function (IRF) and Variance Decomposition (VD). In addition, Error Correcation Model (ECM) was used to investigate the relation between short and long term fluctuations in passenger rail demand. Also the asymmetric cointegration relationship (nonlinear relationship) was investigated between the variables of the model using Enders and Siklos method (Enders and Siklos, 2001). To this end, Threshold Autoregressive (TAR) Model was applied. The result of this estimate pattern is found that there exists asymmetric cointegration relationship between variables.
\end{abstract}

Keywords: Passenger Rail Demand, Tehran Province, Symmetrical and Asymmetrical Cointegration, TAR

\section{INTRODUCTION}

The issue of transportation and its economic impacts is one of the economic issues that attracted the attention of planners of the countries in the world and those who are involved. The impact of transportation on the transfer of passengers and cargos between cities and countries makes it one of the most important means of communication in accessing markets (Verhoef, 2008). Transportation fulfils the need of moving people and cargoes from one point to another one, the provided services in transportation need to be coordinated, extensive, fast, regular comfortable and inexpensive (Weisbrod, 2008). Transportation services are divided into 3 categories of land, marine and airway. Land transportation includes roads (within and 
between cities) and railways (Metro: underground trains - Tram: railways in the city - Railway: regular railways between cities).

Railway systems usually operate on special-made routes, without restriction or any interference from road vehicles. Railways are the common public transportation system in use in some cities in the world which is divided into two types of above ground and underground. Tram is the most common type of aboveground railway and metro is the most common type of underground one. Also, suburban railway system is generally designed for the trips longer than that of metro system and the distance between its stations are also longer. The tracks of this system are usually separated, but they can also have level crossings. Suburban railway services are called express transportation in some parts of metro rails services that the whole or part of which are built underground and have one or several routes and have fixed stations and are accessible through the ground level entrances(Hosseini, 1383).

Transport economics, as a branch of economics, studies transportation networks and their relationship to various sectors of economy of communities (Ja'fari Samimi, 1388). In fact, transportation economy is a branch of economics that by analyzing supply and demand factors, offers the optimum method of using transportation facilities and assets to meet the transportation needs in certain times and places and maximize the positive effects of transportation in different transportation sectors and minimize its negative effects (Mahmoodi, 1376).

The total length of different types of railways is nearly $940 \mathrm{~km}$ and the total number of railway stations are 33 in Tehran Province. According to the recorded history, the railways are built in 1306 and have been continuously used ever since. Like roads, Railways are built and lead to development of its surroundings, so the current study investigates the rail transportation demand in Tehran.

\section{Theoretical Principles}

According to the definition, the demand for a product or service includes various quantity of a product or service that a buyer is willing or capable of buying at different prices, assuming that the rest of the factors are fixed, over a period of time. The overall form of the demand function for the good $X$ can be expressed as follows:

$Q_{x}=f\left(P_{x}, I, P_{y}, T, E, A, \ldots\right)$

Where:

$Q_{x}=$ Demanded quantity (or the purchased amount) for the good $X$

$P_{x}=$ Price of the good $X$

$\mathrm{I}=$ Purchasing power (Income) of consumers

$\mathrm{P}_{\mathrm{Y}}=$ price of the goods related to the good $\mathrm{X}$

$\mathrm{T}=$ Taste of consumers

$\mathrm{E}=$ Consumers' expectation factor

$A=$ Advertisement factor

Therefore, the function of demand for transportation may be considered to be similar to the function of demand for other products and services. Nowadays, due to the wide range of research methods of quantitative estimation in the humanities, including the principles of

www.hrmars.com 
econometrics, linear programming, nonlinear programming and etc., an appropriate model can be applied to estimate any scientific hypothesis, given the nature and ultimate purpose of the research and statistical information available

The study conducted by Fitzroy and Smith provide a theoretical framework for the model used in the current study. They attempted to estimate the rail transportation demand using the time series data for 14 European countries and estimated the effect of variables such as GDP(Gross Domestic Product)per capita, the price of rail transportation, route density ( the ratio of kilometers of railways to square kilometers of the country), frequency ( the ratio of kilometertrain to length of the rout) and oil Prices on demands.

\section{Review of the literature}

In this section the results of some studies are presented, which are explicitly or implicitly related to the present study, so they may be used as guidelines in other sections of the study. Craft (1963) estimates road transportation demand using cross sectional data in his study, in which the elasticity of traveling by bus with respect to the train ticket prices was negative and the elasticity of traveling by train with respect to bus tickets price was estimated as 2.3 . Quandt and Baumol (1966) estimated the transportation demands model using the data of 20 pairs of cities in California in America. Variables such as population of the city, the average income of the city, bank deposits of the city, minimum cost of traveling between the two cities, the relative cost of traveling between the two cities considering the means of transportation, the best travel time between the two cities and the relative duration of travelling between the two cities were entered to the function. The demand income elasticity of the two cities were 1.75 and 3.71 and demand price elasticity was -0.99 .

Alkali (Alkali, 1967) estimated the function of demands for road travelling from Los Angeless to some big cities based on attraction model using regression method and an average distance for each route and entered variables such as travel demand, population of the city and the length of the route. The elasticity of value of travel demand with respect to independent variables of the model were $0.98,1.03$ and -2.25 respectively.

Fisher (1975) used linear models to estimate the function for rail transportation demand in Boston-New York rout. In addition to transportation cost, Fisher entered the time by the means of transportation, bus fares and the amount of car ownership. Then estimated cost elasticity of demands for railway services as $\mathbf{- 1 . 3}$.

Domenkish and Craft (1979) estimated the sensitivity of means of transportation to transportation cost and travel time in Boston to motivate private cars owners to use the public transportation such as metro and bus. Variables such as cost and travel time, cost and travel time of an alternative means of transportation and social variables such as population, employment and income were also entered into the function. The results indicated that the demands for metro and bus transportation were almost not elastic.

Kaemmerle (1989) estimated the demand for airway services in small towns in America. Variables such as the total annual flights, the income of the whole city ' $i$ ', the attraction criteria to reach to the connecting center, the number of weekly direct flights from the city ' $i$ ' to all the airports, an criteria indicating the services with more than 30 seats and the criteria of central 
airport were entered to the function. Income elasticity of transportation supply and demand was estimated as 1.197 and the used parameters in the model were significant ( Ghane Basiri, 1382).

Using the data from 1976-1997 of 34 city pairs in California, Owen and Starki (1997) estimated a model in which variables such as price, population, income, local and cultural influences, and political and governmental factors are used. In order to estimate the model, they considered transportation demand and supply concurrently and applied Two Stage Least Squares (2SLS) method to estimate the model. The estimation showed that the parameters used in the model were significant and elasticities were also calculated.

At Public Administration Training Centre in 1377, A. Ghafurian in his master's thesis titled as 'investigating transportation demands in Rasht province' investigated urban transportation systems and the problems related to the transportation system in Rasht city (Ghafurian, 1377). Various variables such as the number of employed travelers, the purpose of travels including occupational, educational, shopping, going to agencies, receiving services, transporting people, eating, accompaniment, meeting friends, having fun and exercising were entered into the study. The results showed that going to agencies was estimated as 9.21 which was higher than other variables.

In his masters' thesis at faculty of Economics and Accounting, Islamic Azad University, Central Tehran Branch in 1380, S. Mehdizadeh estimated the function for rail services demand in Iran (Mehdizadeh, 1380). The results of the estimation showed that the demand for traveling using railways is influenced by national income and population of the country. T-statistic showed that coefficients of income and population variables were significant.

In their paper titled as 'Travel demand prediction using economic models in rail transport' at Sharif University of Technology in 1382, A. Rezaiee Arjroudi and P. Bazdar Ardebili estimated rail transportation demand using Vector Auto Regression Model and cointegration method for the years 1350-1388 ( A. Rezaiee Arjroudi and P. Bazdar Ardebili, 1382).Using Vector Auto Regression Model, this paper predicted traveling demand variables of per capita income, train ticket price and length of main railway lines. The results indicated that train ticket price and length of main railway lines were exogenous. It means that traveling demand is more affected by income than other variables of the model.

\section{Introducing variables and estimating the model}

As mentioned earlier, the present paper investigated the effect of various factors on rail transportation demand. In so doing, first we introduced the variables and the structure of the model and then estimated the model and presented the results.

\section{Introducing variables}

The variables of the model were:

GDP $/$ POP $=$ Gross Domestic Product at constant prices 1376=100 (Billion rials) / Population (millions) $=$ The per capita income

TD/POP = Transportation Demand (millions) $/$ Population (millions) $=$ Trips per capita 
$P=$ Price of train tickets $=$ Transportation price index with constant price $1376=100 /$ triff of kilometers per person

$X=$ Length of railway lines $(\mathrm{km})$

The variables were extracted and used from statistical yearbook of Tehran Province from the Statistical Centre of Iran for the years 1378-1389 with quarterly status.

\section{Model structure}

Choosing a functional form (linear, logarithmic, semi-logarithmic, etc.) plays an important role in interpreting the estimated coefficients. In case there is a strong theory, it may be used, otherwise an official and accurate test needs to be applied. In cases the dependent variables of both models are the same, the model with higher $\mathrm{R}^{2}$ will be chosen. But if the dependent variables of the two models are not the same, choosing only $\mathrm{R}^{2}$ criterion is not enough and the dependent variable should be scaled in a way that the both models can be compared. This method is based on the work of COX and BOX and is known as COX-BOX.

Considering the study conducted by Fitzroy and Smith regarding rail transportation demand and based on COX-BOX test and lower value of RSS (residual sum of squares) in a logarithmic model, the model is determined as follows: ( $L=$ Logarithm)

$L T D / P O P=\beta_{0}+\beta_{1} L G D P / P O P+\beta_{2} L P+\beta_{3} L X+u_{t}$ 


\section{Stationarity test of variables}

Investigating the stationarity of the model's variables is one of the required stages of estimating the regression model and is done to avoid false regression (Shirinbaskhsh, 1376). To this end, Augmented Dickey-Fuller (ADF) test is used. The results are presented in table 1.

Table1. Results of the stationarity test of variables (source: exported from Eview7 software)

\begin{tabular}{|c|c|c|}
\hline \multirow[t]{2}{*}{ Variable } & \multicolumn{2}{|c|}{ Augmented Dickey-Fuller (ADF) } \\
\hline & Statistic & Critical Values \\
\hline \multirow{3}{*}{ LTD/POP } & \multirow{3}{*}{-3.50} & -3.59 \\
\hline & & -2.93 \\
\hline & & -2.60 \\
\hline \multirow{3}{*}{ LGDP/POP } & \multirow{3}{*}{-3.43} & -4.18 \\
\hline & & -3.51 \\
\hline & & -3.18 \\
\hline \multirow{3}{*}{ LP } & \multirow{3}{*}{-3.99} & -4.18 \\
\hline & & -3.51 \\
\hline & & -3.18 \\
\hline \multirow{4}{*}{ LX } & \multirow{4}{*}{-2.82} & -3.61 \\
\hline & & -2.93 \\
\hline & & -2.60 \\
\hline & & \\
\hline
\end{tabular}

Regarding the statistics of the test, first difference of all of statistics are stationary. However, in order to ensure the existence of the long term and balanced relation, cointegration test is needed to be conducted.

\section{Investigating cointegration of variables}

Considering the stationarity of the model's variables in first difference, the cointegration of the variables was investigated using Vector Autoregression Model (VAR). Therefore, by using the guidelines of the optimum lag, VAR model was selected with respect to Akaike information 
criterion(AIC), Schwartz information criterion(SC), Hannan-Quinn information criterion(HQ), Final prediction error( FPE) and LR test statistic(LR). Based on these criteria, the optimum lag of VAR(Vector Autoregression Model) was 2. After this stage, the cointegration of the model was evaluated. In the desired lag and based on $\lambda_{\text {Trace and }} \lambda_{\max }$, the variables of the model were cointegrated. Therefore, it can be said that there is a long term and balanced relation among these variables. The following long term and balanced relation for variables is resulted from the estimated cointegration vectors.

LTD/POP $=0.575740 L G D P / P O P-3.285087 L P+1.712463 L X$

Independent variables coefficients in this relation show the elasticity of demand function regarding each of the factors affecting the demand function ( Ayazi, 1380). Therefore, the elasticity of transportation demand function to income, train ticket price and length of rail lines are $0.515140,-3.285087$ and 1.712643 respectively.

\section{Investigating the dynamism of the VAR model}

In order to investigate the dynamism of the model, the two criteria of impulse response function(IRF) and variance decomposition(VD) were used, so the two criteria of the model were calculated and analyzed.

\section{Impulse response function(IRF)}

By applying an impulse (shock) of one standard deviation from each of variables, the criteria observes the reaction of other variables. In fact, it can be called 'dynamic multiplier' and shows the reaction of each variable to the applied shock from the same variable of other ones (Shirin Bakh, 1386). As can be seen in figure 1, the reaction of rail transportation demand to income per capita is a positive one and an indicator of a positive trend.

Response of LTDIPOP to LGDPIPOP

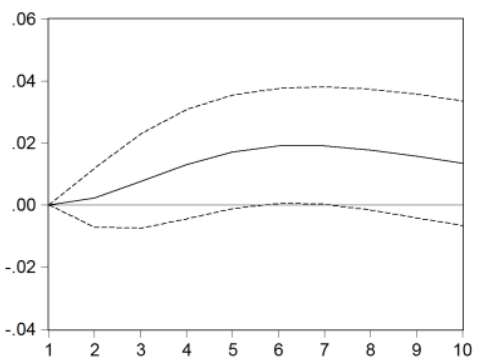

Figure1-The diagram of rail transportation demand reaction to income per capita (Source: exported from Eviews7)

Also, the reaction of this variable to the price of train tickets is fluctuating. The result is shown in figure 2.

wWw.hrmars.com

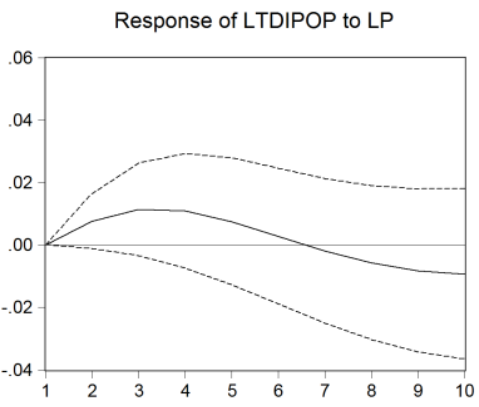


Figure 2- The diagram of rail transport demand reaction to the price of train ticket (Source: exported from Eviews 7)

The reaction of rail transportation demand to the length of railway line is also positive. The result is presented in figure 3 .

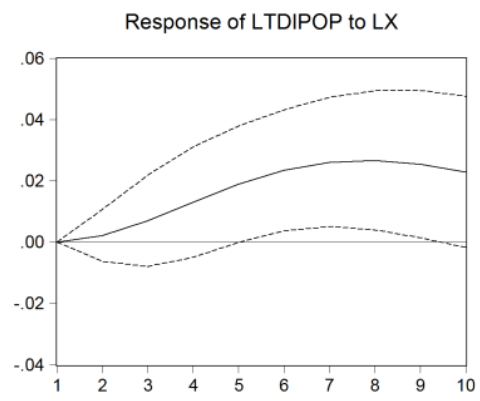

Figure 3-The diagram of rail transportation demand reaction to the length of railway lines (Source: exported from Eviews 7)

\section{Variance decomposition (VD)}

Variance decomposition is another criteria that can be used to investigate the dynamism of the model and evaluate the relative importance of each variable to justify the changes in the same variable and other variables (ShirinBakhsh, 1386). According to the results, the relative share of length of rail line was more than the other two variables of train ticket price and income per capita. This fact is indicative of relative importance of this variable compared with the variables of train ticket price and income per capita in rail transportation demand behavior in Tehran province. It means that the length of rail line has the highest contribution to the changes of rail transportation demand.

\section{Vector Error Correction Model (VECM)}

This model evaluates the movements of short term fluctuations towards long-term balance. Therefore, the short term fluctuations of a variable will be related to its long term value. When in econometrics there is a cointegration between variable, the error correction model can be estimated (Enders, 2004). Adjustment coefficient resulted from this model shows the adjustment rate of fluctuations and its movement towards equilibrium. In the present study, the adjustment rate of rail transportation demand is -0.04 which indicate that each year about 4 percent of imbalance is corrected in short term. Therefore, the short term fluctuations of rail transportation demand slowly tends to its balanced values in long term period. This coefficient is indicative of low rate correction of imbalances in rail transportation demand. The relation of is vector error correction model is as follows:

$\mathrm{D}(\mathrm{LTD} / \mathrm{POP})=0.418106 \mathrm{D}(\mathrm{LTD} / \mathrm{POP}(-1))-0.049822 \mathrm{D}(\mathrm{LTD} / \mathrm{POP}(-2))-0.373703 \mathrm{D}(\mathrm{LGDP} / \mathrm{POP}(-1))$ $+0.253287 \mathrm{D}(\mathrm{LGDP} / \mathrm{POP}(-2))+1.332370 \mathrm{D}(\mathrm{LP}(-1))-0.239608 \mathrm{D}(\mathrm{LP}(-2))-0.043486 \mathrm{D}(\mathrm{LX}(-1))$ 


\section{Asymmetric Cointegration}

In case the long term adjustment process of variables is asymmetric, Engle -granger test may have an error and its result may not show the nature of the relation between the variables. The cointegration of the desired variables was investigated using the resulted error terms. The results is presented in table2. According to the following table, the error term is stationary for the three assurance levels of $90 \%, 95 \%$ and $99 \%$; therefore, the variables are also cointegrated in this model.

Table 2. Results for error term stationarity test ( source: exported from EViews7)

\begin{tabular}{|c|c|c|c|c|}
\hline \multirow{2}{*}{ Error term } & \multirow{2}{*}{ ADF Statistic } & $\% 1$ & $\% 5$ & $\% 10$ \\
\cline { 3 - 4 } & & & & \\
\hline $\begin{array}{c}\text { Income per capita, } \\
\text { train ticket price, } \\
\text { the length of rail } \\
\text { line }\end{array}$ & -4.75 & -2.63 & -1.95 & -1.61 \\
\hline
\end{tabular}

Therefore, the method introduced by Enders \& Siklos was used to investigate the asymmetric cointegration. In this method, first the long term relation between the variables was estimated and then the resulted error term was used to calculate the indicator function in the threshold autoregressive model(Shu-Chen Chang ,2008). In TAR model, the indicator function 'It', is determined as follows:

$I_{t}=\left\{\begin{array}{l}1 \text { if } \varepsilon_{t-1} \geq 0 \\ 0 \text { if } \varepsilon_{t-1}<0\end{array}\right.$

Then, asymmetric cointegration was tested in the next step using the results from threshold autoregressive model.the model is as follows:

$$
\Delta \varepsilon_{t}=I_{t} \rho_{1} \widehat{\varepsilon}_{t-1}+\left(1-I_{t}\right) \rho_{2} \widehat{\varepsilon}_{t-1}+\sum_{t=1}^{k} \delta_{i} \Delta \widehat{\varepsilon}_{t-i}+\xi_{t}
$$

The results of using the model is presented in the following table, Wald test is used in this mehod to test the two nul hypotheses of $H_{0}=\rho_{1}=\rho_{2}$ and $H_{0}=\rho_{1}=\rho_{2}=0$. According to the results of the test, since the resulted risk levels and the calculated $F$ Implie the rejection of null hypotheses, there is a cointegration relation between the variables of the model. 
Table3. asymmetrical cointegration using TAR model (source: exported from Eviews7)

\begin{tabular}{|c|c|c|c|c|c|}
\cline { 2 - 5 } \multicolumn{1}{c|}{} & \multicolumn{2}{c|}{ TAR } & \multicolumn{2}{c|}{ TAR } \\
\cline { 2 - 5 } \multicolumn{1}{c|}{} & \multicolumn{2}{c|}{$\mathrm{H}_{0}=\rho_{1}=\rho_{2}=0$} & & \multicolumn{2}{c|}{$\mathrm{H}_{0}=\rho_{1}=\rho_{2}$} \\
\hline Model & $\mathrm{F}$ & Prob & $\begin{array}{c}\text { Optimal } \\
\text { lag }\end{array}$ & $\mathrm{F}$ & Prob \\
\hline $\begin{array}{c}\text { Income per capita, } \\
\text { train ticket price, } \\
\text { length of rail lines }\end{array}$ & 14.52563 & 0.0000 & 1 & 4.833357 & 0.0332 \\
\hline
\end{tabular}

\section{CONCLUSION}

According to the calculations and the expressed descriptions about the model, the following results are achieved.

1-First difference of the variables are stationary. Applying Johansen test to investigate the cointegration approved that the relation is a balanced and long term one, so the long term relation was estimated.

2-The achieved results are consistent with theoretical existence, as the train ticket price variable have a negative correlation with the quantity of demand for rail transport, but the variables of income per capita and length of rail lines have a positive correlation with amount of rail transportation demand.

3-Considering the fact that variables have a balanced long term logarithmic relation, the coefficients show the elasticity of the quantity of rail transportation demand with respect to independent variables of the model.

4-Results of IRF and VD criteria show that the length of rail lines have a higher contribution to the changes of rail transportation demand than other variables. It means that the length of rail lines have the highest contribution to the changes of rail transportation demand.

5-Engle-granger method is used to evaluate the long-term balanced relation between variables of the model; however, since it is possible for variables to have non-linear relationship, other methods of econometrics of non-linear time series like Enders and Siklos is applied to investigate asymmetrical cointegration (non-linear relationship). At the end of the study, the above-mentioned method is applied to investigate the cointegration of variables and the results are indicative of asymmetrical cointegration of variables of the model.

\section{REFERENCES}

Ayazi, A. (2001), Selected Main Topics of Microeconomics. Tehran: Allameh Tabatabaee' University.

Enders, W. and Siklos, P.L. (2001), Cointegration and Threshold Adjustment. Journal of Business and Economic Statistic, 19: 166-176

Enders, W. (2004), Applied Econometric Time Series. Alabama: University of Alabama. 
Faghfurian, A. (1998), Investigating Transport Demand in Rasht City. Public Administration Training Center.

FitzRoy, F. and Smith, I. (1998), Passenger Rail Demand in 14 Western European Countries: A

Comparative Time Series Study, International Journal of Transport Economics, Vol. 25, pages 299-312.

Ghane Basiri, M. (2003), Estimating the Demand Function for Fuel in Iranian Air Transportation in 1361-1382. Faculty of Economics and Accounting, Islamic Azad University Central Tehran Branch, Iran.

Heimonen, k. (2006), Nonlinear Adjustment in PPP-evidence from Threshold Cointegration. Empirical Economics. Vol. 31, pages 479-495.

Hosseini, Mohammad (2004), Planning of Transportation Engineering and Analysis of Material Handling. Tehran: Publication Center of Iran University of Science and Technology.

Jafari Samimi, A. (2009), Comparative Advantage of the Transportation Industry in Iran. Islamic Azad University-Firoozkuh Branch, Tehran Province,Iran.

Mahmoodi, A. (1997), Transport Economics. Tehran: Institue for Trade Studies and Research.

Mehdizadeh, S. (2001), Estimation and Analysis of Rail Transportation Services in Iran. Faculty of Economics and Accounting, Islamic Azad Central Tehran Branch, Iran.

Rezaei Arjerudi, A. (2010), Investment and Impact of Investment on the Economic Growth of the Country's Rail Transport. Twelfth International Conference on Rail Transport. Iran.

Rezaei Arjerudi, A. , Bazadar Ardebili, P. (2003), Travel Demand Prediction Using Economic Models in Rail Transport. Seventh International Conference on Transport. Sharif University of Technology.

Saeednia, Sh. (2007), Using Eviwes in Econometrics. Tehran: Institute of Economic Affairs.

Shirinbakhsh, Sh. and Hasan khonsary, Z. (2006), Application of Eviews in Econometrics, Tehran: Alzahra University.

$\mathrm{SCl}$, (2011). Statistical Center of Iran Report, Iran.

Verhoef, E. (2008), Toll Competition in Transport Networks, Journal of Transport Economic and Policy, Vol. 6, pages 361-366.

Weisbrod, G. (2008), Models to Predict the Economic Development Impact of Transportation Projects, Annals of Regional Science, Vol. 42, No 3 